\title{
PERENCANAAN PRODUKSI KERAJINAN KULIT KERANG MUTIARA \\ DENGAN MENGGUNAKAN METODE AGREGAT \\ DI KOTA AMBON
}

\author{
Marcy L. Pattiapon ${ }^{1)}$, Nil Edwin Maitimu ${ }^{2)}$ \\ e-mail: ${ }^{1)}$ marcylolita_unpatti@yahoo.com, ${ }^{2}$ Edwinmaitimu@yahoo.com \\ Program Studi Teknik Industri, Fakultas Teknik Universitas Pattimura - Ambon
}

\begin{abstract}
ABSTRAK
Maluku merupakan daerah kepulauan yang kaya akan hasil alam terutama laut yang diantaranya yaitu kerang mutiara. Salah satu industri kecil yang cukup berkembang adalah industri kerajinan dari kulit kerang mutiara, kulit kerang mutiara di manfaatkan dan di olah sebagai kerajinan yang bernilai seni tinggi merupakan salah satu ciri khas dari daerah Maluku yang merupakan salah satu pilihan cinderamata yang cukup diminati oleh wisatawan dalam negeri maupun luar negeri. Kerang selain dikonsumsi, kerang juga menghasilkan mutiara dan sering dibuat menjadi perhiasan seperti kalung, gelang, cincin dan hiasan dinding dan berbagai aksesoris.

Terjadinya fluktuasi permintaan dari waktu ke waktu menyebabkan perlunya perencanaan persediaan dengan melakukan peramalan kebutuhan dimasa yang akan datang.Peramalan yang digunakan adalah Time Series Moving Average dan Single Exponential Smoothing.

Hasil penelitian yang dilakukan dapat diketahui bahwa yang menyerap modal terbesar adalah kerangmutiara, profil, kain bludru dan kaca. Peramalan dengan Moving Average (MA) = 4 bulan mempunyai nilai error tekecil dengan hasil prakiraan peramalan adalah $57 \mathrm{~kg}$. Dengan total biaya sebesar Rp. 5.156.847.779.Alternatif yang digunakan dalam perencanaan agregat adalah strategi dengan hari kerja regular tetap dan strategi lembur, yaitu selama 26 hari/bulan, dengan kapasitas produksi 39 unit produk jadi kulit kerang. Dengan total biaya adalah sebesar Rp. 243.650.000.
\end{abstract}

Kata Kunci: Perencanaan Persediaan, Forecasting, Agregat

\section{PENDAHULUAN}

Maluku merupakan daerah kepulauan yang kaya akan hasil alam terutama laut yang diantaranya yaitu kerang mutiara. Salah satu industri kecil yang cukup berkembang adalah industri kerajinan dari kulit kerang mutiara, kulit kerang mutiara di manfaatkan dan di olah sebagai kerajinan yang bernilai seni tinggi merupakan salah satu ciri khas dari daerah Maluku yang merupakan salah satu pilihan cinderamata yang cukup diminati oleh wisatawan dalam negeri maupun luar negeri. Kerang mutiara adalah biota laut yang bertubuh lunak atau moluska yang hidup dilaut, tubuhnya dilindungi oleh sepasang cangkang yang tipis dan keras. Kerang selain dikonsumsi, kerang juga menghasilkan mutiara dan sering dibuat menjadi perhiasan seperti kalung, gelang, cincin dan hiasan dinding dan berbagai aksesoris. Desa Batu Merah merupakan sebuah tempat usaha pengrajin kulit kerang mutiara yang sekaligus memasarkan produk yang dihasilkan, dalam melakukan pengadaan bahan baku masih dengan cara tradisional atau dengan berdasarkan perkiraan. Jenis - jenis produk yang dihasilkan dari kulit kerang mutiara cukup beragam dengan motif- motif yang menarik di antaranya bermotif kuda liar, kaligrafi dan taman getsemani. Untuk saat ini tercatat ada sekitar 16 unit usaha namun yang termasuk pengrajin sebanyak 9 unit.
Selama ini para pengrajin melakukan pengendalian persediaan bahan baku kerajinan kerang mutiara hanya berdasarkan pengalaman dan pemahaman yang sederhana. Terjadinya fluktuasi permintaan dari waktu ke waktu mengharuskan perencanaan persediaan bahan baku dilakukan untuk memenuhi kebutuhan produksi mendatang, namun tetap memperhatikan biaya persediaan yang akan dikeluarkan oleh pengrajin. Perencanaan persediaan yang dilakukan perlu memperhatikan tingkat kepentingan barang yang dapat ditinjau dari tingkat kekritisan barang, kecepatan pemakaian atau tingkat keuntungan yang dapat diraih dan berdasarkan tingkat penyerapan modal.

\section{LANDASAN TEORI}

\section{Defenisi dan Tujuan Peramalan}

Peramalan adalah suatu perkiraan tingkat permintaan yang diharapkan untuk suatu produk atau beberapa produk dalam periode waktu tertentu dimasa yang akan datang. Tujuan utama dari peramalan permintaan adalah untuk meramalkan permintaan dari item-item independent demand (permintaan terhadap material, produk yang tidak terkait langsung dengan struktur (bill of material) dimasa yang akan datang. 


\section{Analisa Deret Waktu}

Rata-rata Bergerak (Moving Average (MA))

Moving Average diperoleh dengan rata - rata permintaan berdasarkan data masa lalu yang terbaru.Tujuan utama dari penggunaan teknik MA ini adalah untuk mengurangi atau menghilangkan variasi acak permintaan dalam hubungannya dengan waktu.

$$
=\frac{\begin{array}{llllll}
k & -r & B & & k-p \\
& & d_{i} & n-p & t_{i} & h u
\end{array}}{n}
$$

dimana $\mathrm{n}$ adalah banyaknya periode dalam rata-rata bergerak.

\section{Pemulusan Eksponensial Smoothing (ES)}

Model peramalan pemulusan eksponensial dilakukan berdasarkan formula berikut :

$$
F_{L}=F_{L-1}+\alpha\left(A_{L-1}-F_{L-1}\right)
$$

\section{Persediaan}

Persediaan adalah sumber daya menganggur (idle resources) yang menunggu proses lebih lanjut (Nasution, 1999). Persediaan dapat berupa bahan baku untuk keperluan proses, barang-barang yang masih dalam pengolahan dan barang jadi yang disimpan untuk dijual.

\section{Model Persediaan}

\section{Model Persediaan Bahan Baku Dengan EOQ}

Model ini digunakan untuk menentukan berapa jumlah bahan baku ataupun produk yang harus dipesan untuk meminimumkan biaya penyimpanan persediaan. Menurut Tersine (1994) Persediaan memiliki tujuan agar perusahaan dapat membeli atau membuat item dalam jumlah ekonomis. EOQ merupakan jumlah pemesanan yang dapat meminimumkan total persediaan. Rumus EOQ adalah seabagai berikut :

$$
Q^{*}=\sqrt{\frac{2 C \cdot K}{H}}=\sqrt{\frac{2 C \cdot K}{P \cdot F}}
$$

\section{Model Persediaan Dengan Backorder}

Terjadinya kekurangan pada suatu periode tertentu, maka kekurangan bahan baku kulit kerang mutiara akan dipenuhi di kemudianhari (backorder).
Diasumsikan bahwa kekurangan persediaan bahan baku kulit kerang mutiara akan dipenuhi pada pengiriman pesanan berikutnya. Hal ini yang menyebabkan seringkali jumlah item yang di backorder dalam kondisi negatif, artinya jumlah tersebut yang harus dipenuhi dikemudian hari untuk memenuhi kekurangan yang terjadi.

$$
Q^{*}=\sqrt{\frac{2 C}{H}} \sqrt{\frac{H+K}{K}}
$$

\section{Perencanaan Agregat}

Perencanaan produksi agregat berangkat dari permasalahan adanya ketidakseimbangan antara permintaan dan kemampuan produksi pada setiap periode perencanaan. Hal ini karena secara umum tingkat permintaan suatu produk selalu tidak samaantara periode satu ke priode lain.

\section{Sistem Klasifikasi ABC}

Klasifikasi $\mathrm{ABCmembagi}$ persediaan menjadi tiga kelas berdasarkan atas nilai persediaan sehingga dapat diketahui item mana yang harus mendapat perhatian lebih bila dibandingkan dengan item yang lainnya. Sedangkan nilai yang dimaksud dalam klasifikasi $\mathrm{ABC}$ ini bukanlah harga persediaan per unit, melainkan volume persediaan yang dibutuhkan dalam satu periode dikalikan dengan harga per unitnya.

\section{METODOLOGI PENELITIAN}

Metodologi penelitian merupakan landasan agar proses penelitian berjalan secara sistematis, terstruktur dan terarah sehingga mencapai tujuan yang telah ditetapkan sebelumnya.

\section{PENGUMPULAN DAN PENGOLAHAN DATA}

\section{Peramalan Permintaan}

Data permintaan kerajinan kulit kerang mutiara pada desa Batu Merah Ambon dari bulan Juni 2013 sampai dengan bulan Mei 2016. 
Tabel 2. Data Permintaan Kulit Kerang Desa Batu Merah

\begin{tabular}{|c|c|c|}
\hline Periode & $\begin{array}{l}\text { Periode } \\
\text { Waktu }\end{array}$ & Data \\
\hline Juni'13 & 1 & 65 \\
\hline Juli & 2 & 40 \\
\hline Agustus & 3 & 70 \\
\hline September & 4 & 45 \\
\hline Oktober & 5 & 60 \\
\hline November & 6 & 78 \\
\hline Desember & 7 & 55 \\
\hline Januari '14 & 8 & 63 \\
\hline Februari & 9 & 47 \\
\hline Maret & 10 & 59 \\
\hline April & 11 & 67 \\
\hline Mei & 12 & 75 \\
\hline Juni & 13 & 46 \\
\hline Juli & 14 & 50 \\
\hline Agustus & 15 & 72 \\
\hline September & 16 & 48 \\
\hline Oktober & 17 & 57 \\
\hline November & 18 & 63 \\
\hline Desember & 19 & 49 \\
\hline Januari'15 & 20 & 50 \\
\hline Februari & 21 & 67 \\
\hline Maret & 22 & 78 \\
\hline April & 23 & 65 \\
\hline Mei & 24 & 167 \\
\hline Juni & 25 & 200 \\
\hline Juli & 26 & 74 \\
\hline Agustus & 27 & 48 \\
\hline September & 28 & 156 \\
\hline Oktober & 29 & 176 \\
\hline November & 30 & 64 \\
\hline Desember & 31 & 79 \\
\hline Januari'16 & 32 & 56 \\
\hline Februari & 33 & 78 \\
\hline Maret & 34 & 49 \\
\hline April & 35 & 59 \\
\hline Mei & 36 & 42 \\
\hline
\end{tabular}

Tabel 2. Analisa Kesalahan

\begin{tabular}{|c|c|c|c|c|c|c|}
\hline \multicolumn{7}{|c|}{ Analisa Kesalahan } \\
\hline & F1 & F2 & F3 & F4 & F5 & F6 \\
\hline MAD & 26.14 & 27.15 & 28.55 & 27.38 & 27.53 & 27.79 \\
\hline MAPE & 33.95 & 34.94 & 36.42 & 37.36 & 37.94 & 38.52 \\
\hline MSE & 1445.51 & 1546.02 & 1702.53 & 1654.07 & 1711.82 & 1738.76 \\
\hline
\end{tabular}

Berdasarkan data permintaan bahan baku utama yaitu kulit kerang mutiara selama periode waktu 36 bulan dimana dalam pengolahan data permintaan ini digunakan dua metode peramalan sebagai pembanding. Adapun kedua metode tersebut adalah metode Single Moving Average dan metode Single Eksponential Smoothing. Metode Single Moving Average (MA) yang digunakan adalah MA (4), MA (5) dan MA (6). Sedangkan metode Single Eksponential Smoothing menggunakan $\alpha=0.8, \alpha=$
0.9 dan $\alpha=0.95$. Berdasarkan analisa kesalahan yang digunakan maka kesalahan peramalan terkecil terdapat pada metode Moving Average 4 bulan atau MA (4).

\section{Model Persediaan Bahan Baku Dengan EOQ}

Berdasarkan hasil perhitungan diatas, maka periode waktu perencanaan adalah sebesar $57 \mathrm{~kg}$ kulit kerang mutiara. Dari sejumlah permintaan tersebut diatas, maka jumlah pesanan ekonomi kulit kerang mutiara 
yang dapat dilakukan perusahaan adalah $29.367 \mathrm{~kg}$ kulit kerang mutiara. Sehingga dapat dikatakan bahwa dalam satu tahun perencanaan, perusahaan memesan $29.367 \mathrm{~kg}$ kulit kerang tiap 5 hari sekali atau 61 kali dalam satu tahun.

\section{Model Persediaan Dengan Backorder}

Dari perhitungan diatas maka dapat disimpulkan bahwa pemesanan ekonomis mengalami peningkatan dari $29.387 \mathrm{~kg}$ menjadi $398.69 \mathrm{~kg}$ kulit kerang. Pada saat perusahaan mengambil kebijakan backorder, maka ongkos menurun pada ongkos total pemesanan sebasar Rp. 5.156.847.779 - Rp. 51.052.650 = Rp. 5.105.795.129. Dengan waktu tunggu yang sama yaitu 5 hari.

\section{Perencanaan Kapasitas Produksi}

Tabel 3. Analisa Kesalahan

\begin{tabular}{|c|c|c|c|c|c|c|}
\hline \multicolumn{7}{|c|}{ Analisa Kesalahan } \\
\hline & F1 & F2 & F3 & F4 & F5 & F6 \\
\hline MAD & 16.45 & 17.59 & 18.61 & 17.36 & 17.76 & 17.92 \\
\hline MAPE & 744.19 & 816.1 & 890.55 & 841.47 & 874.16 & 889.89 \\
\hline MSE & 33.68 & 35.71 & 36.67 & 37.89 & 39.32 & 39.99 \\
\hline
\end{tabular}

Berdasarkan data permintaan produk jadi kulit kerang mutiara selama periode waktu 36 bulan dimana dalam pengolahan data permintaan ini digunakan dua metode peramalan sebagai pembanding. Adapun kedua metode tersebut adalah metode Single Moving Average dan metode Single Eksponential Smoothing. Metode Single Moving Average (MA) yang digunakan adalah MA (4), MA (5) dan MA (6). Sedangkan metode Single Eksponential Smoothing menggunakan $\alpha=0.8, \alpha=$ 0.9 dan $\alpha=0.95$. Berdasarkan analisa kesalahan yang digunakan maka kesalahan peramalan terkecil terdapat pada metode Moving Average 4 bulan atau MA (4).

\section{Perhitungan Model Distribusi Dari Aggregat Planning}

Setelah melakukan perhitungan dengan menggunakan model transportasi dengan menggunakan data-data yang diperoleh dari pihak perusahaan maka diperoleh Total Cost sebesar Rp.243.650.000.

\section{Kesimpulan}

Kesimpulan yang diperoleh adalah sebagai berikut :

a. Perencanaan dan Pengendalian Produksi

- Metode peramalan yang digunakan untuk menentukan peramalan bahan baku utama kulit kerang mutiara untuk periode mendatang adalah metode Moving Average (4 bulan). Hasil peramalan untuk periode mendatang adalah sebesar $57 \mathrm{~kg}$ bahan baku kulit kerang mutiara.
- Jumlah pesanan ekonomis adalah sebesar $29 \mathrm{~kg}$ yang dipesan sebanyak 61 kali dalam satu tahun dengan interval pemesanan setiap 5 hari sekali. Sedangkan ongkos total persediaan yang dikeluarkan adalah sebesar Rp. 5.156.847.779.

b. Perencanaan agregat

- Metode prakiraan untuk menentukan prakiraan bahan baku kulit kerang 1 periode mendatang adalah metode moving average (4). Hasil prakiraan untuk 1 tahun adalah 39 unit.

- Alternatif yang digunakan dalam perencanaan agregat adalah strategi dengan hari kerja regular tetap dan strategi lembur, yaitu selama 26 hari/bulan, dengan kapasitas produksi 39 unit produk jadi kulit kerang. Dengan total biaya adalah sebesar Rp. 243.650.000.

\section{DAFTAR PUSTAKA}

Bedworth, D.D. and J.E. Bailey. 1987. Integrated Production Control Systems: Management, Analysys, Design. Second Edition. New York: John Wiley andSons.

Gaspersz, V. (2004), Production Planning And Control. PT. Gramedia Pustaka Utama, Jakarta.

Handout Perencanaan dan Pengendalian Produksi, ITB, Bandung, 2004.

Makridakis, S.dan Wheelwright S C., Metode dan Aplikasi Peramalan Jilid 1, Jakarta:

Erlangga, 1991

Nasution, A. H. (1999), Perencanaan dan Pengendalian Produksi. Guna Widya, Jakarta. 